Journal of Physical Oceanography, Vol. 22, No. 1, pp. 83-92 (1992)

10.1175/1520-0485(1992)022<0083:BWCITW >2.0.CO;2

\title{
Bottom Water Circulation in the Western North Atlantic ${ }^{*}$
}

\author{
KEVIN G. SPEER \\ Institut für Meereskunde, Kiel, Germany \\ Michael S. MCCARTNEY \\ Woods Hole Oceanographic Institution, Woods Hole, Massachusetts
}

(Manuscript received 3 August 1990, in final form 8 May 1991)

\author{
ABSTRACT
}

\begin{abstract}
Antarctic Bottom Water flows into the western North Atlantic across the equator, shifting from the western side to the eastern side of the trough between the American continents and the Mid-Atlantic Ridge as it continues north. This is puzzling because such large-scale motion is thought to be controlled by dynamics that disallows an eastern boundary current. Previous explanations for the transposition involve a (necessarily small-scale) density current that changes sides because of the change in sign of rotation across the equator, or a topographic effect that changes the sign of the effective mean vorticity gradient and thus requires an eastern boundary current. Here an alternative explanation for the overall structure of bottom flow is given.

A source of mass to a thin bottom layer is assumed to upwell uniformly across its interface into a less dense layer at rest. A simple formula for the magnitude of the upwelling and thickness of the layer is derived that depends on the source strength to the bottom layer. For a strong enough source, the bottom layer thickness is zero along a grounding curve that separates the bottom water from the western boundary and confines it to the east. A band of recirculating interior flow occurs, supplied by an isolated northern and western boundary current. Similar structures appear to exist in the Antarctic Bottom Water of the western North Atlantic.
\end{abstract}

\section{Introductions}

Dense plumes from both Arctic and Antarctic regions enter the North Atlantic Ocean on the bottom at its northern and southern extremities (Worthington and Wright 1970). Although the extreme chemical signal of the polar source water for these currents has greatly diminished by mixing along their path, they remain sufficiently distinct to be traced around the Atlantic. In the north, the Denmark Strait overflow forms the densest water and fills the deepest parts of the trough between the American continents and the Mid-Atlantic Ridge with water that is relatively salty compared to the Antarctic source water entering at the equator. The Denmark Strait overflow continues flowing southward as a bottom boundary current in the west into the South Atlantic. On the other hand, water from the south enters at the equator and flows north, at first more or less on the western side of the trough, but it soon separates from the western boundary and flows north in the central and eastern parts of the trough (Fig. 1; Whitehead $* W$
7563.

* Woods Hole Oceanographic Institution Contribution Number Corresponding author address: Dr. Kevin Speer, Institut für Meereskunde, Düsternbrooker Weg 20, D-2300 Kiel, Germany. and Worthington 1982; Fuglister 1960). Finally, this water reaches the northern limit of the basin at the Newfoundland Ridge and turns west and south as a current or system of currents apparently isolated from the main body of Antarctic Bottom Water (Weatherly and Kelley 1985).

Wright (1970) explained that on crossing the equator, the bottom water flow ought to turn right under the influence of rotation. While this statement ought to be relevant near the equatorial source, the large scale of the western basin rules out such a density current explanation for the overall structure of the flow. Furthermore, the coldest bottom water is found on the western side of the trough, from $3^{\circ} \mathrm{N}$ up to a latitude of about $8^{\circ} \mathrm{N}$ (Whitehead and Worthington 1982; Fuglister 1960). The separation from the western boundary at low latitude is something of a puzzle, because according to Stommel and Arons' (1960) deep circulation dynamics, the interior ought to be supplied by a northward-flowing western boundary current extending up to midlatitudes.

Bottom topography can give rise to two important effects, which could dramatically change the Stommel and Arons pattern. First, a north-south slope can change the effective mean vorticity gradient felt by the bottom layer, possibly changing the direction of interior flow and the location of boundary currents. Warren (1981) suggested that this effect might have a role in 

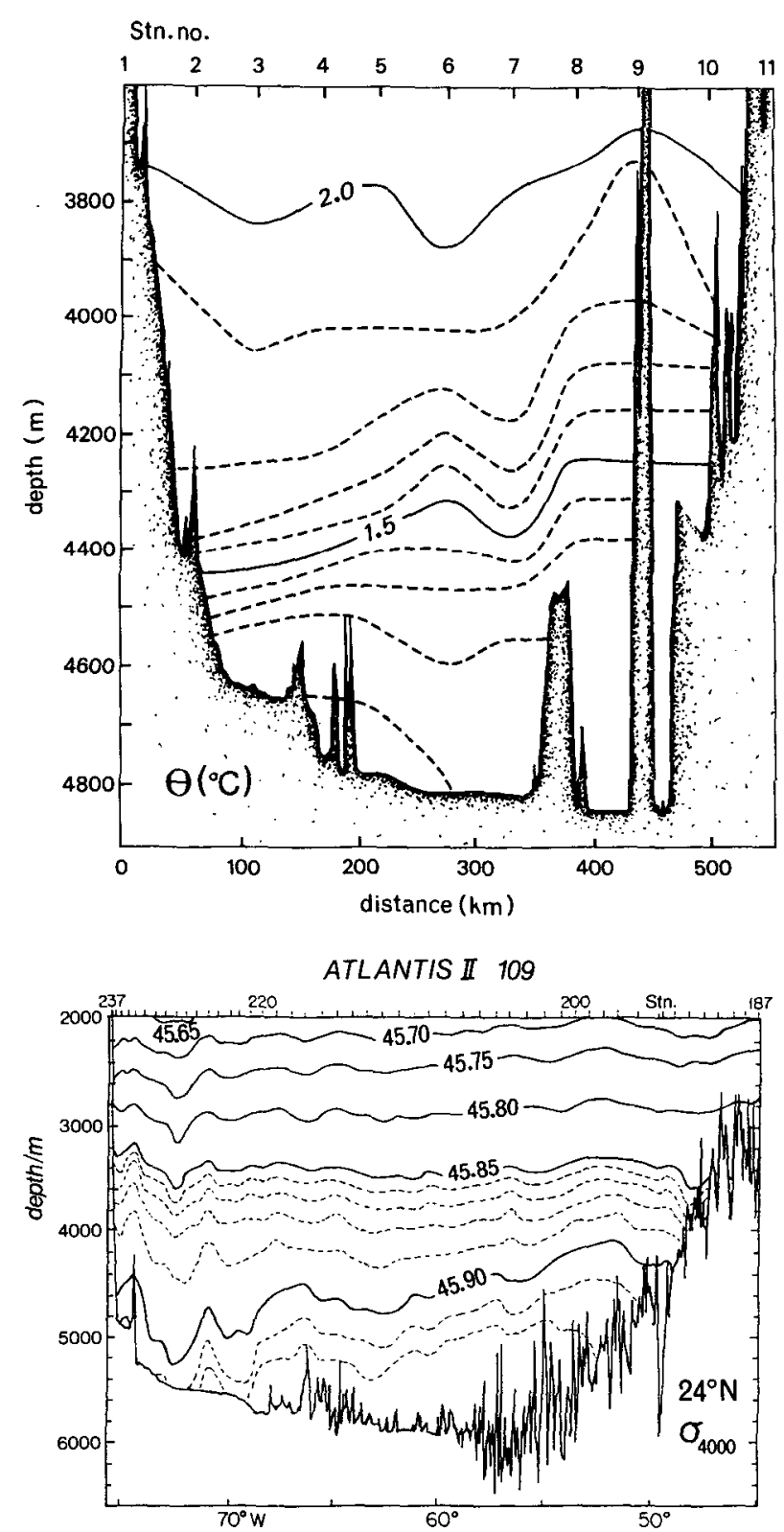

Fig. 1. (a) Deep profile of potential temperature from $6^{\circ}$ to $9^{\circ} \mathrm{N}$ across the western trough of the North Atlantic, adapted from Whitehead and Worthington (1982). (b) Deep profile along $24^{\circ} \mathrm{N}$ of potential density anomaly referenced to $4000 \mathrm{db}\left(\mathrm{kg} \mathrm{m}^{-3}\right)$.

the evident concentration of flow on the eastern side of the trough. Second, the decrease in the area of a level surface with depth resulting from topography can generate anticyclonic (clockwise in the Northern Hemisphere) motion in the rising fluid as it moves outward toward the sloping boundary (Rhines and McCready 1989; Speer and Tziperman 1990). In the western Atlantic the flow spans regions of increasing as well as decreasing bottom depth without apparent strong perturbation to the northward flow and general cyclonic circulation, so these effects do not have an obvious crucial role.

Observations of the density structure of deep and bottom water in the western North Atlantic show strong variations throughout the interior region, as opposed to variations confined to eastern or western boundary regions alone (Fig. 1; Fuglister 1960). North of about $12^{\circ} \mathrm{N}$ there does not appear to be a lateral boundary layer in the east at all: the flow in the interior accounts for all of the northward flow. Although several basic features of property distributions can be explained within the framework of the Stommel and Arons (1960) model applied to a bottom layer, variations in layer thickness are excluded by assumption. In this study the bottom layer thickness is fixed only at the eastern boundary and is allowed to vary across the interior in a manner consistent with the vertical shear. For certain combinations of eastern boundary-layer thickness and bottom water source strength, the isopycnal dividing bottom and deep water grounds, thus, separating the bottom water from the western boundary. Some related ideas about the connection between the thermal wind and bottom currents were outlined by Saunders (1987) in the context of flow through the Discovery Gap in the eastern North Atlantic. The dynamical mechanism of grounding is similar to that of outcropping proposed by Parsons (1969) and Luyten et al. (1983) for the subpolar gyre.

Kawase (1987) offered an explanation for the eastward confinement of Antarctic Bottom Water in which the setup of the basin circulation pattern is frozen at an early stage by strong damping. At the early stage of setup, long planetary waves have not had time to remove the eastern boundary currents created by Kelvin waves, and if the damping is strong the long waves are themselves trapped in the east. The model presented here avoids his arbitrary damping parameter (although strong assumptions about cross-isopycnal upwelling are made) and attempts to explain the transposition of bottom water in terms of simple, large-scale dynamics rather than boundary layers.

To model the flow of bottom water, a single moving layer underneath another at rest is used. In the first part of the discussion of the model, the upwelling is specified. In the second part, the fundamental driving is the source strength of bottom water, rather than a specified upwelling. In principle, the source can be measured and perhaps even related to air-sea fluxes and mixing, while the upwelling is difficult to observe and furthermore ought to be calculated as part of the circulation problem. This is not really done here, since the upwelling is assumed to be uniform, but as a small step the uniform upwelling is solved for, rather than specified. This is not entirely trivial, since the area of the bottom water depends on the upwelling when grounding occurs. By doing this, the bottom layer solution can be expressed in terms of a single, in principle, observable parameter. The central result giving the 
separation latitude in terms of a single parameter is derived for this system. Estimates of this parameter from measurements are given. Some effects of an eastern boundary sink are discussed, representing the Vema Fracture Zone at $11^{\circ} \mathrm{N}$ through which water passes into the eastern trough. In contrast to the case without an eastern boundary sink, a separated boundary current is required if the separation latitude is equatorward of the sink, since the "zonal" jet supplying the sink can no longer reach the western boundary.

\section{The model}

The model presented here takes for granted a uniform upward "vertical" velocity (positive cross-isopycnal velocity) at the interface over a flat bottom. This requires northward interior flow in the model, consistent with the observation of broad interior northward flow in the deepest parts of the western basin (Fig. 1).

The model geometry is a rectangular basin of width $L$ and length $2 L$, extending from the equator to a latitude meant to be the latitude of the Newfoundland Ridge at $40^{\circ}-43^{\circ} \mathrm{N}$ (Fig. 2). The equatorial $\beta$-plane approximation is used, with the Coriolis parameter $f$ $=\beta y$. are

The momentum and mass conservation equations

$$
\begin{gathered}
f v=g^{\prime} h_{x} \\
f u=-g^{\prime} h_{y} \\
u_{x}+v_{y}+w_{z}=0,
\end{gathered}
$$

where $x, y, u, v$ are the zonal and meridional directions and speeds, positive east and north, $h$ is the layer thickness, $g^{\prime}=g \Delta \rho / \rho$ where $g$ is gravity, $\Delta \rho$ is the density difference between the bottom layer and the layer above, and $\rho$ is the bottom layer density. The equations can be integrated vertically to the top of the layer where, since they are steady and geostrophic, the change in layer thickness following the fluid columns is zero, or $d h / d t=0$. That is, the flow is parallel to contours of constant $h$. To maintain a steady layer thickness in the presence of an upwelling, an entrainment velocity at the interface is assumed to compensate:

$$
w=\frac{d h}{d t}+w_{e}=w_{e} .
$$

In the following, $w$ is the upwelling cross-isopycnal velocity. Combining the above equations gives the vorticity and $h$ equations

$$
\begin{gathered}
\beta v h=f w \\
\frac{\partial h^{2}}{\partial x}=\frac{2 f^{2} w}{\beta g^{\prime}} .
\end{gathered}
$$

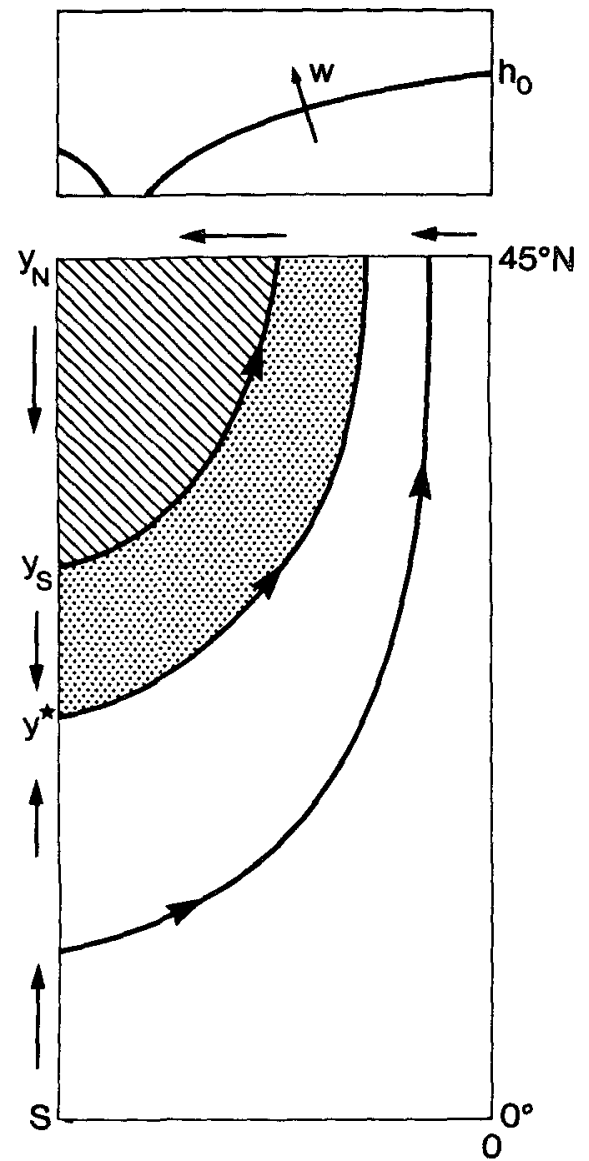

FIG. 2. Schematic of the bottom layer model, plan view, and cross section north of $y_{s}$. The equatorial source $S$ supplies a western boundary current that flows north as far as $y^{*}$. An isolated northern boundary current carries water west, turns, and becomes a western boundary current, which feeds the interior between $y_{s}$ and $y^{*}$ forming a recirculation (stippled). The region where bottom water is absent is hatched.

The new feature here is the variable layer thickness, as opposed to the Stommel and Arons model in which the pressure varies but the thickness is constant.

\section{a. Interior flow}

For simplicity, assume that $w$ is uniform. Integrating in $x$ with $h=h_{o}$ on the eastern boundary where $x=0$,

$$
h^{2}=h_{o}{ }^{2}+\frac{2 f^{2} x w}{\beta g^{\prime}} .
$$

Substituting $f=\beta y$ gives

$$
h^{2}=h_{o}{ }^{2}+\frac{2 \beta w x y^{2}}{g^{\prime}} .
$$

It is clear from the vorticity equation $\beta v=f w / h$ that the speed is infinite on the curve $h=0$. The transport, 
however, is finite everywhere and equal to the usual Stommel and Arons interior transport; ${ }^{1}$

$h v=\frac{1}{2 f} g^{\prime}\left(h^{2}\right)_{x}=w y, \quad h u=\frac{1}{2 f} g^{\prime}\left(h^{2}\right)_{y}=-2 w x$.

Given the upwelling $w$, the structure of $h$ is determined. At latitude $y, h$ decreases westward from $h_{o}$ to $\left(h_{o}^{2}-2 \beta w L y^{2} / g^{\prime}\right)^{1 / 2}$ at $x=-L$. The layer thickness $h$ depends on the familiar form $x y^{2}$, as does pressure in the standard Stommel and Arons model on an equatorial $\beta$ plane. On a curve of constant thickness, the right-hand side of

$$
-x y^{2}=\frac{g^{\prime}\left(h_{o}^{2}-h^{2}\right)}{2 \beta w}
$$

is constant and shows the tendency for isopleths to be squeezed toward the origin as $w$ increases. In fact, they can be compressed to such an extent that for large enough $w$, the special isopleth $h=0$ appears within the domain. This "grounding" curve intersects the western boundary $(x=-L)$ at the latitude

$$
y_{s}=\left(\frac{g^{\prime} h_{o}^{2}}{2 \beta L w}\right)^{1 / 2}
$$

obtained by substituting $h=0$ into (11).

Thus, along the western boundary, the layer thickness decreases to zero at $y_{s}$, at which latitude the bottom layer separates from the western boundary and is confined to the eastern part of the basin (Fig. 2). Using the natural scale $w L / h_{o}$ for the horizontal velocity $U$, the scale for $y_{s}$ can be written

$$
y_{s}=L\left(\frac{\beta g^{\prime} h_{o} / f^{2}}{L} \frac{L}{U}\right)^{1 / 2} .
$$

Physically, the factors in parenthesis represent the ratio of the advective time scale to the adjustment time scale for long planetary waves. If the advective time scale is short, the thermal wind restricts the westward extent of the bottom layer, cutting it off beyond the point

\footnotetext{
1 To remove the infinite speeds on the grounding curve, a different distribution of upwelling is required: one that is also zero when the thickness is zero. The choice of the distribution is arbitrary and based only on analytical simplicity, so consider the choice $w=w_{o} h / h_{o}$, which satisfies the above condition. Integrating the vorticity equation as before gives$$
h=h_{0}+\frac{\beta w_{o} y^{2} x}{g^{\prime} h_{o}} .
$$

Now $h$ depends linearly on $x$ and the flow speed is uniform across the wedge-shaped bottom layer. The transport, of course, is concentrated in the east, where the layer is thickest. Other forms for upwelling in terms of $h$ were tried and produce a variety of bottom layer shapes, but the overall structure remained more or less the same, since the equation separates into a function of $h$ on one side and a function of $x y^{2}$ on the other.
}

$x=-g^{\prime} h_{o}^{2} / 2 \beta w y^{2}$. Although the total zonal thickness change north of $y_{s}$ is constant, $h_{o}$, the meridional transport decreases as rotation increases. This decrease balances the water leaving through upwelling.

How strong must the upwelling be to force the layer to separate at relatively low latitude? For $y_{s}=2000$ $\mathrm{km}$ (about $\left.18^{\circ} \mathrm{N}\right), w=g^{\prime} h_{o}{ }^{2} / 2 \beta L y_{s}{ }^{2}=4 \times 10^{-5}$ $\mathrm{cm} \mathrm{s}^{-1}$, using the values $g^{\prime}=0.1 \mathrm{~cm} \mathrm{~s}^{-2}, h_{o}=400 \mathrm{~m}$, $\beta=2 \times 10^{-13} \mathrm{~cm}^{-1} \mathrm{~s}^{-1}$, and $L=2500 \mathrm{~km}$. The source strength necessary to supply such an upwelling across the reduced area of the bottom layer is roughly $3 \times 10^{6}$ $\mathrm{m}^{3} \mathrm{~s}^{-1}$. For comparison, if the bottom layer extended across the entire basin (as in the usual Stommel and Arons regime), the same upwelling over a greater area requires a source strength of about $7 \times 10^{6} \mathrm{~m}^{3} \mathrm{~s}^{-1}$. For these choices of $\Delta \rho, h_{o}, L$, and $w$, though, the layer cannot extend across the basin. To show the connection between the grounded layer regime and the usual Stommel and Arons situation, the source strength should be fixed and the amplitude of the upwelling calculated (section $2 b$ ). Then the changes needed to make a transition from one regime to the other become clear. In the next section the grounding condition will be rederived in nondimensional form to make the key parameter explicit, and, in addition, the question of closing the interior flow with boundary currents is addressed.

\section{b. Closing the interior flow}

From here on, the variables are nondimensional, with the scales $h \sim h_{o}, x, y \sim L, w \sim S / 2 L^{2}$, where $S$ is the net source strength, and $f=\beta y$. The equation for thickness becomes

$$
h^{2}=1+\frac{x y^{2} w}{\lambda}, \quad \lambda=\frac{g^{\prime} h_{o}{ }^{2}}{\beta S L} .
$$

Here the fundamental forcing is the source strength $S$. At this point the upwelling $w$ is unknown, since we do not yet know the area of the bottom layer. The thickness $h$ can be zero for some range of $\lambda$ and $w$. On this grounding curve, $x y^{2}=-\lambda / w$. The point on the western boundary where this occurs is $h\left(x=-1, y_{s}\right)$ $=0$ and defines the separation latitude $y_{s}=(\lambda / w)^{1 / 2}$.

The parameter $\lambda$ may be written as

$$
\lambda=\frac{\beta g^{\prime} h_{o}}{\beta^{2} L^{3}} \frac{L^{2} h_{o}}{S}=\frac{\tau_{r}}{\tau_{a}},
$$

where $\tau_{r}$ is the residence time and $\tau_{a}$ is the adjustment time scale for long planetary waves to cross the basin from east to west. Long waves tend to carry the eastern boundary condition westward, flattening out the bottom layer. On the other hand, a short residence time implies a strong shear, which stalls the long waves and drives the interface into the ground. If the residence time is short compared to the adjustment time, the waves are blocked and eastward confinement occurs. 
Kawase's (1987) parameter $\delta=g h_{o} / \lambda \beta L^{3}$ may be interpreted in a similar fashion, since his $\lambda$ represents a parameterization of upwelling as a damping term in the layer thickness equation. A related parameter for the near-surface circulation is $g^{\prime} h_{o}{ }^{2} / L \tau$ (Huang 1984), where $h_{0}$ is now the top-layer eastern boundary condition and $\tau$ is the wind stress. Both $S$ and $\tau$ drive vertical motion, and to make the connection between the two parameters the Ekman vertical-velocity scale $\tau / f L$ can be replaced by the upwelling scale $S / A$.

The relation between the net source, upwelling, and area of the bottom layer gives a relation between $w$ and $\lambda$. The total area of the bottom layers can be divided into that south $\left(A_{1}\right)$ and north $\left(A_{2}\right)$ of $y_{s}$ :

$$
\begin{gathered}
A_{1}=y_{s} \\
A_{2}=\int_{y_{s}}^{y_{N}} \frac{\lambda}{w} \frac{d y}{y^{2}} .
\end{gathered}
$$

The total area of the bottom layer decreases as $w$ increases. Substituting for $y_{s}$ and choosing $y_{N}=2$ in the relation $w\left(A_{1}+A_{2}\right)=2$ gives

$$
\begin{aligned}
& w=\lambda\left(\lambda^{-1}+\frac{1}{4}\right)^{2}, \\
& y_{s}=\frac{1}{\left(\lambda^{-1}+1 / 4\right)} .
\end{aligned}
$$

Now that we know $w(\lambda)$, the layer thickness and interior flow are fully determined by $\lambda$. For $\lambda>4$ (a value specific to the model geometry), the bottom layer covers the entire basin and $w=1$ (Fig. 3). As $\lambda$ decreases, due, for instance, to a stronger source, the area also decreases as the upwelling intensifies. This can also be understood physically as a result of holding $h_{o}$ constant so that the residence time $\tau_{r}$ decreases while the adjustment time $\tau_{a}$ remains the same, blocking the westward penetration of long waves sooner. Then separation occurs at a lower latitude. For example, a sep-

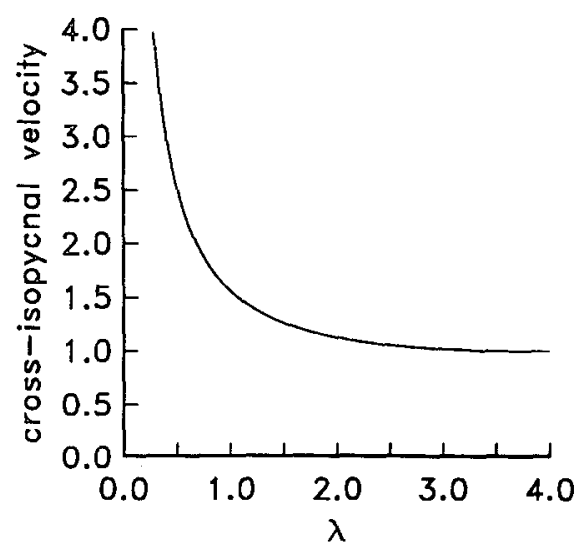

FIG. 3. Cross-isopycnal velocity $w$ (scaled by $S / 2 L^{2}$ ) versus $\lambda$.

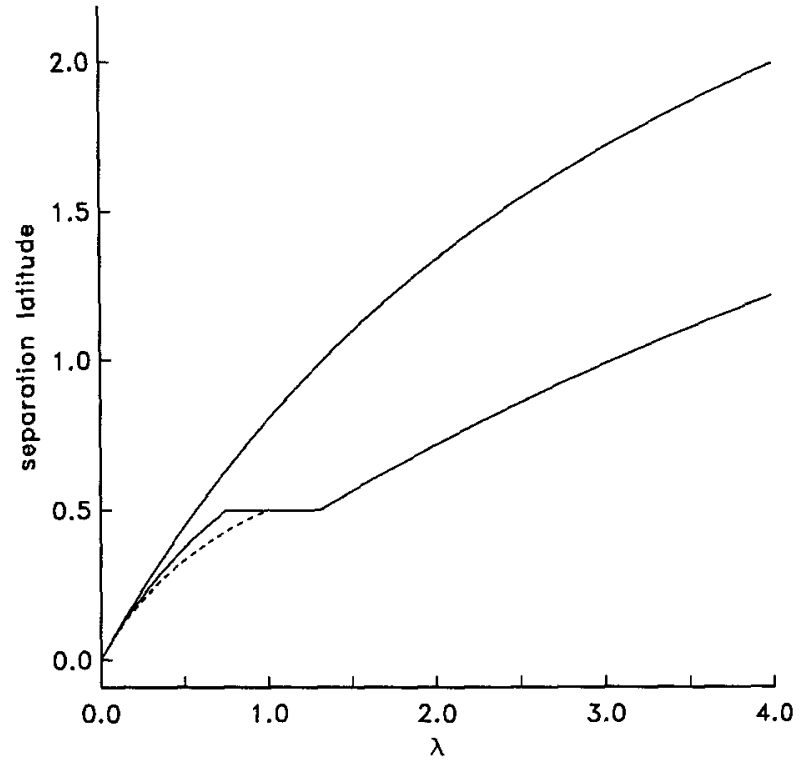

FIG. 4. Separation latitude $y_{s}$ (scaled by $L$ ) versus $\lambda$. Standard case is the smooth line. Two examples with a Vema Fracture Zone sink are also shown, for $h_{N}=0.6$ (with step), and $h_{N}=0$ (dashed).

aration latitude at roughly $10^{\circ} \mathrm{N}\left(y_{s}=0.5\right)$ would suggest a value for $\lambda$ of about 0.5 (Fig. 4).

We have calculated the interior flow, but what happens to the water that runs into the northern boundary? To see how the mass budget is closed in the basin as a whole, including northern and western boundary currents, consider the point $y^{*}$ on the western boundary where the transport of the northward-flowing current from the equatorial source goes to zero (Fig. 2). The mass divergence out of this current is constant in $y$, $u h=w$, and the net loss amounts to $S$ at the latitude $y^{*}$ defined by

$$
w y^{*}=1 \text {. }
$$

As $w$ is never less than one, the maximum northward penetration along the western boundary $y^{*}$ is always equatorward of midbasin. Furthermore, the western boundary current runs out of water at a latitude south of the separation latitude $y_{s}$ ( since $w>\lambda^{-1}$ ). Thus, in addition to the loss of water from the interior to a northern boundary current at $y_{N}$, there is a source of water to the interior from a western boundary current between $y^{*}$ and $y_{s}$ that is not supplied from the equatorial source $S$.

The recirculation transport that leaves the interior and enters the northern boundary current at $y_{N}$ is the integral of $v h$ across the layer at the northern boundary. This is $T_{r}=\lambda / 4$, or dimensionally, $T_{r}=g^{\prime} h_{o}{ }^{2} / 2 \beta y_{N}$, since the layer thickness changes by $h_{o}$ from the eastern boundary to the grounding curve. The amount of water noted above entering the interior between $y^{*}$ and $y_{s}$ from the western boundary current is $u h$ times the distance $\left(y_{s}-y^{*}\right)$. This is $w\left(y_{s}-y^{*}\right)=\lambda / 4=T_{r}$. The 
source and sink match, and it is therefore presumed that an isolated boundary current is formed at the northern boundary, flows west and then south as an isolated western boundary current, and enters the interior between $y^{*}$ and $y_{s}$. Hence, the northwest sector of the basin, where the densest bottom water is absent, is surrounded on all sides by denser water, just as lowerlayer water in a surface outcropping region may be ringed by less-dense water. The structure of the isolated boundary current is not analyzed here (see Huang 1984 , for a discussion of this problem).

Another qualitative difference between this model and that of Stommel and Arons is the presence of a transport maximum in the interior at latitude $y_{s}$, since poleward of this latitude the interior is no longer fed by a boundary current. In the south the transport increases linearly $(w y / 2)$, while in the north it decreases as rotation increases $(\lambda / 2 y)$. The Stommel and Arons model has transport increasing linearly all the way to the northern boundary (Fig. 5).

One feature of the circulation that should be important to the distribution of properties is the age of the recirculated water. In a band initially between $y^{*}$ and $y_{s}$ on the western boundary extending up to the northern boundary, the water is not directly supplied by the equatorial source and ought to have characteristics much less distinctive as a result of mixing occurring in the interior (where speeds are low and residence time long) and along the boundary (where residence time is short but the flow is strong).
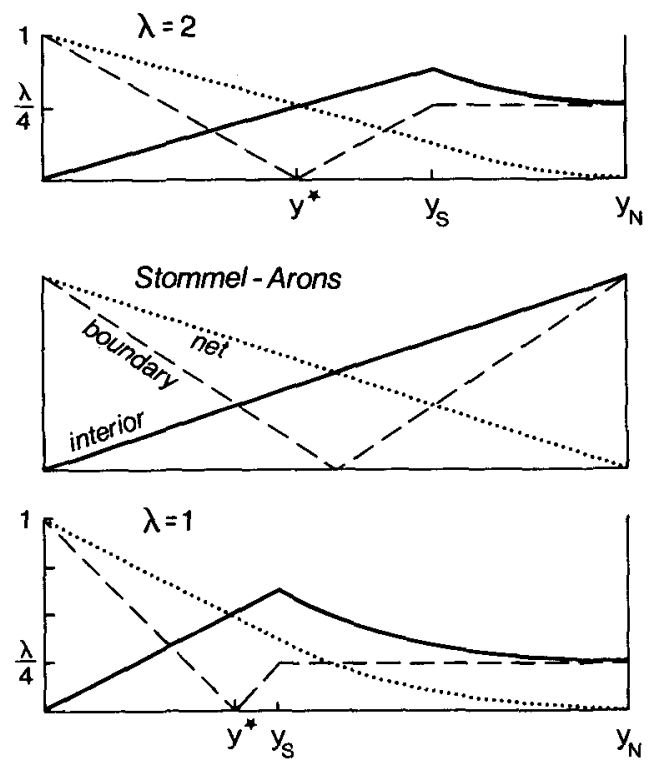

FIG. 5. Interior (solid), boundary (dashed), and net (dotted) transport magnitudes as a function of latitude for $\lambda=2$ (upper), $\lambda$ $=1$ (lower), and for the Stommel and Arons model (middle). The boundary transport reverses direction at $y^{*}$.
This completes the description of the model. Several questions arise concerning the application of the model to bottom water circulation in the western North Atlantic. First of all, do estimates of $\lambda$ suggest that grounding may occur? Second, how does the presence of a sink at the Vema Fracture Zone modify the grounding curve; and third, would the existence of a moving deep layer above the bottom layer eliminate the grounding regime? These questions seem to be of immediate importance and some progress on their resolution is reported in the following sections.

\section{c. Estimate of $\lambda$ from observations}

Successfully translating the model results to the ocean depends to a great extent on a good estimate of $\lambda$. This, in turn, requires a definition of the bottom layer, since the ocean is not made up of homogeneous layers. In practice, the bottom layer may be defined as all water denser than a given value. The reduced gravity $g^{\prime}$, layer thickness along the eastern boundary $h_{o}$, and the mass source $S$ all vary with density, so different choices of interface density produce different values of $\lambda$. These factors are estimated over some range near the transition from Antarctic Bottom Water to North Atlantic Deep Water in this section, to see if the resulting values for $\lambda$ indicate a regime in which we expect grounding or, on the contrary, the traditional Stommel and Arons regime. The division between the two regimes is based on the condition that $y_{s}$ be within the basin, i.e., $y_{s}<y_{N}$. Using $y_{s}=1 /\left(\lambda^{-1}+1 / 4\right)$ gives $\lambda$ $<\lambda_{s}=4$ as the condition on $\lambda$.

At the transition to dense bottom water near 4000 $\mathrm{m}$ depth, the density increases by about $0.1 \times 10^{-3}$ $\mathrm{g} \mathrm{cm}^{-3}$, so a reasonable value for $\mathrm{g}^{\prime}$ is $0.1 \mathrm{~cm} \mathrm{~s}^{-2}$. The thickness of the bottom layer at $4^{\circ} \mathrm{N}$ is about $400 \mathrm{~m}$, and this is the value taken for $h_{o}$. The net source $S$ of water colder than $2^{\circ} \mathrm{C}$, say, can in principle be calculated from direct flow measurements and hydrographic observations at the equator and. the Vema Fracture Zone-the entrance and exit locations for water at those high densities. The flow through the Vema Fracture Zone has recently been estimated to be close to 2 $\times 10^{6} \mathrm{~m}^{3} \mathrm{~s}^{-1}$ (McCartney et al. 1991), thus making Wright's (1970) estimate of $2.8 \times 10^{6} \mathrm{~m}^{3} \mathrm{~s}^{-1}$ for the northward flow of bottom water at $8^{\circ} \mathrm{N}$ and Whitehead and Worthington's (1982) figure of about $2 \times 10^{6}$ $\mathrm{m}^{3} \mathrm{~s}^{-1}$ at $4^{\circ} \mathrm{N}$ seem too small. It is clear that the Vema Fracture Zone does not remove all of the bottom water that enters, so a plausible choice of $4 \times 10^{6} \mathrm{~m}^{3} \mathrm{~s}^{-1}$ will be used here for the net source $S$. With $\beta=2$ $\times 10^{-13} \mathrm{~m}^{-1} \mathrm{~cm}^{-1}$ and $L=2500 \mathrm{~km}$, the value of $\lambda$ is about 1.5. Therefore, according to the model, there ought to be grounding. A different model geometry could change the critical value, but plausible choices of basin dimensions all result in values of order one.

Without rather good constraints on the net source of bottom water at various densities, it is difficult to 
attach much significance to a particular value of $\lambda$. However, by comparing the dependence of vertical velocity on $\lambda$ with observations, some additional support for the model may be found. Whitehead and Worthington (1982) presented mass budgets for a number of layers making up bottom water, having divided it into temperature classes separated by $0.1^{\circ} \mathrm{C}$. Within the bottom water, the $T-S$ relation is quite constant and so one may ignore the distinction between temperature and density for the purpose of estimating $\lambda$ from their results. Their calculations thus seem perfectly suited to test the application of the model to the ocean over a range of densities. To correct for the seemingly low values of the total source, each layer source was doubled, raising the total to $4 \times 10^{6} \mathrm{~m}^{3} \mathrm{~s}^{-1}$. The estimation was made by summing the adjusted layer source and thickness cumulatively from the coldest layer on up. The average thickness was obtained by dividing the layer volume by the average of the top and bottom area, taking into account Whitehead's (1989) revised areas. Using $\beta$ and $L$ as before, but now with $g^{\prime}=0.01 \mathrm{~cm} \mathrm{~s}^{-2}$, vertical velocity $w$ may be plotted versus $\lambda$ (Fig. 6).

In order to compare these data to the model curve $w(\lambda)$, the vertical velocity must be scaled. The value at $\theta=1.9^{\circ} \mathrm{C}$ was used as a scale since it represents the
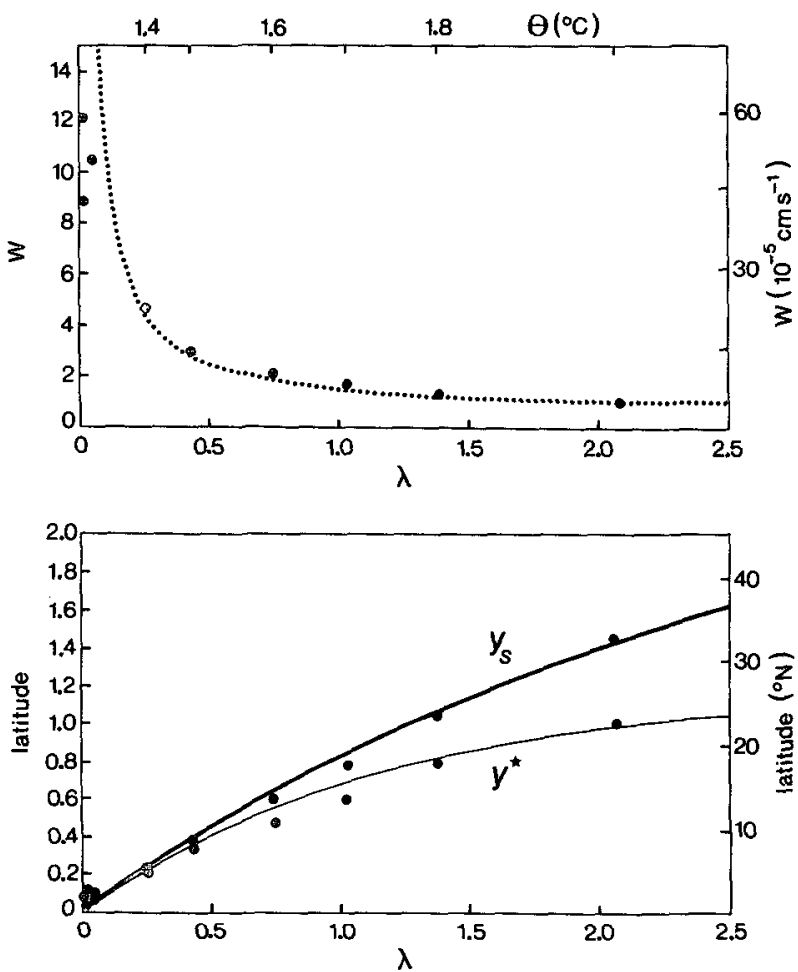

FIG. 6. Adjusted vertical velocity (see text) in bottom water at several temperatures plotted versus $\lambda$, together with $w=\lambda\left(\lambda^{-1}\right.$ $+0.22)^{2}$ (upper). Corresponding plots of separation latitude $y_{s}=(\lambda)$ $w)^{1 / 2}$ and boundary current reversal latitude $y^{*}=1 / w$ (lower).
TABLE 1. Potential temperature on two isobaths along the western boundary. The coldest values are used at latitudes $4^{\circ} \mathrm{N}, 6^{\circ} \mathrm{N}$, and $8^{\circ} \mathrm{N}$, where the depth never reaches $4900 \mathrm{~m}(*)$; these values occur on the western side. Data at $8^{\circ} \mathrm{N}$ and $16^{\circ} \mathrm{N}$ are from Fuglister (1960); the rest are from more recent Woods Hole Oceanographic Institution cruises.

\begin{tabular}{rcc}
\hline & \multicolumn{2}{c}{$\theta\left({ }^{\circ} \mathrm{C}\right)$} \\
\cline { 2 - 3 } & $4500 \mathrm{~m}$ & $4900 \mathrm{~m}$ \\
\hline $4^{\circ} \mathrm{N}$ & 1.1 & $1.0^{*}$ \\
$6^{\circ} \mathrm{N}$ & 1.4 & $1.1^{*}$ \\
$8^{\circ} \mathrm{N}$ & 1.6 & $1.2^{*}$ \\
$13^{\circ} \mathrm{N}$ & 1.8 & 1.6 \\
$16^{\circ} \mathrm{N}$ & 1.8 & 1.7 \\
$24^{\circ} \mathrm{N}$ & 1.9 & 1.8 \\
$36^{\circ} \mathrm{N}$ & 1.9 & 1.9 \\
\hline
\end{tabular}

estimated upwelling across a surface spanning the entire basin. The qualitative behavior of $w$ is like that in the model. For a quantitative comparison, the curve $w$ $=\lambda\left(\lambda^{-1}+0.22\right)^{2}$ is shown. It was obtained by adjusting the single, model dependent constant using a nonlinear fitting routine. The three data points at the lowest values of $\lambda$ had to be excluded from the fit; their disagreement may be due to a poor estimate of thickness (Whitehead 1989) or the failure of the model to account for the area of the coldest layers, perhaps because topography and friction are neglected. At the same time, the good agreement at larger $\lambda$ may be fortuitous, since it depends on layer source strengths that are not well known.

Once $w$ is estimated, the expected separation latitude $y_{s}=(\lambda / w)^{1 / 2}$ and boundary-current reversal latitude $y^{*}=w^{-1}$ may be plotted as well (Fig. 6, lower). For convenience, the latitude in degrees has been plotted on the right using the scale $L=2500 \mathrm{~km}$. The coldest isotherms separate at quite low latitudes, which illustrates again the difficulty in comparing a simple layer model to the continuously stratified ocean. Nevertheless, the expected separation of the isotherms from the western boundary is in rough agreement with the observed increase in temperature along the western side of the trough at 4900-m depth (Table 1 ).

The boundary-current reversal latitude $y^{*}$ is problematic. It clearly has little meaning for the coldest isotherms, which are imbedded in northward flow, but it does suggest a boundary current reversal for the warmest Antarctic Bottom Water between $1.8^{\circ}$ and $1.9^{\circ} \mathrm{C}$ near $20^{\circ} \mathrm{N}$. The recirculation band should then be centered around $30^{\circ} \mathrm{N}$. We regard these comparisons as promising, and we wish to address the key issues of boundary current reversal and the recirculation band in a sequel paper.

Probably the most crucial problem with the interpretation of these curves as support for the model is that the variation of $w$ may result from topography as well as grounding (Rhines and McCready 1989; Speer and Tziperman 1990). These studies show the impor- 
tant role that hypsometry has on the $w$-depth curve. This study, on the other hand, shows that when grounding occurs, there is a kind of dynamic hypsometry that also modifies $w$. Both of these effects tend to increase $w$ near the bottom, but distinguishing them demands a model with realistic bottom depth.

\section{d. Vema Fracture Zone}

Water flowing through the Vema Fracture Zone at $11^{\circ} \mathrm{N}$ influences the bottom layer, both by reducing the net source of water to the basin and by causing the layer thickness to decrease across the gap at the eastern boundary, by an amount related to the sink strength (Fig. 7). The new eastern boundary condition north
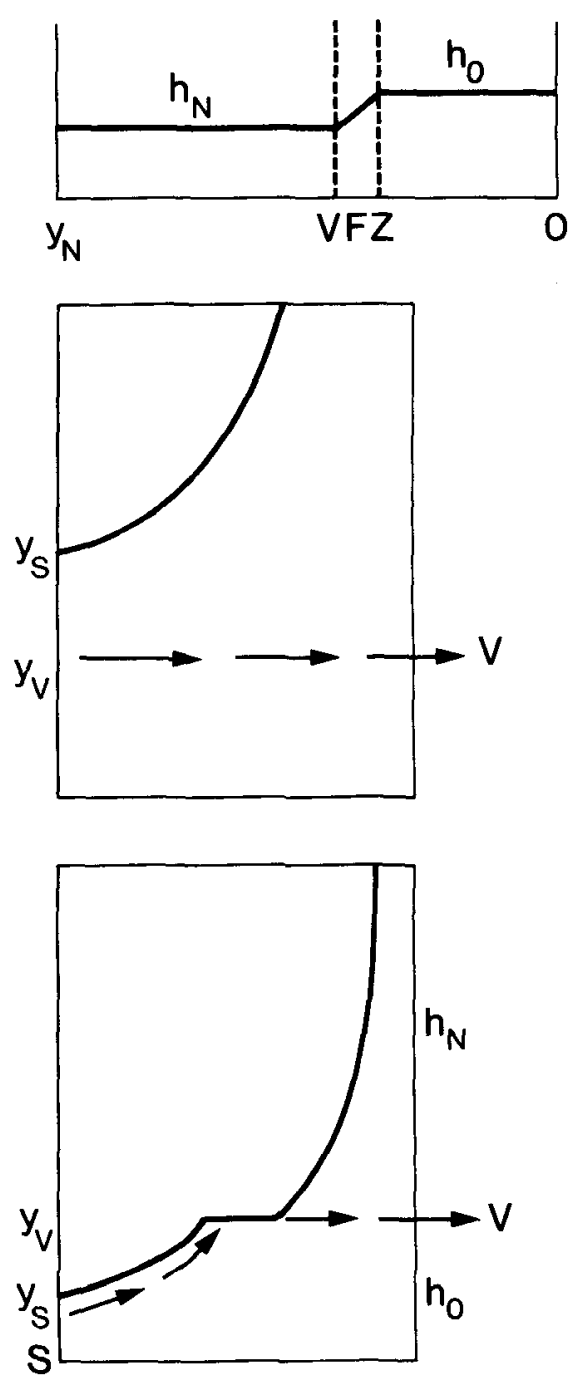

FIG. 7. Schematic of the model with an eastern boundary sink. The eastern boundary condition changes across the fracture zone consistent with the transport out of the basin (upper). Separation north of $y_{v}$ (middle). Separation south of $y_{v}$ (lower); the flow out of the basin is deflected from the latitude line $y=y_{v}$. of the fracture zone modifies the interior circulation, and in particular can change the location of the curve $h=0$

Two cases need to be distinguished. If the separation latitude is north of the latitude of the fracture zone, then the situation is basically the same as before, but with $h_{o}$ in $\lambda$ replaced by its northern equivalent $h_{N}$ (Fig. 7, middle). If $y_{s}$ is south of the fracture zone then the curve $h=0$ has a step in it owing to the sink (Fig. 7 , lower). The sudden change in transport at the latitude $y_{v}$ changes the layer thickness, hence the expressions for area to the north and to the south. Redoing the area calculation gives

$$
w=\lambda^{-1}\left(1+\frac{\lambda h_{N}^{2}}{4}-\frac{\lambda h_{N}^{2}}{2 y_{v}}+\frac{\lambda}{2 y_{v}}\right)^{2},
$$

where $y_{v}$ is the latitude of the fracture zone and $h_{N}$ is scaled by $h_{o}$.

Consider an eastern boundary sink located at $y_{v}$ $=0.5$ of strength $V$. The relation between $y_{s}$ and $\lambda$ for $y_{s}>y_{v}$ is given by (19) with $h_{o}$ replaced by $h_{N}$. With $h_{N}=0.6, y_{s}$ is greater than $y_{v}$ only for values of $\lambda$ greater than about 1.3 (Fig. 4). Below this value the new relation for area must be used. The two curves thus produced do not meet, and there is a range of $\lambda$ near $\lambda$ $=1$ for which the separation latitude remains constant at $y_{v}$. The reason for this behavior is that as the source strength increases and $\lambda$ decreases, the added thickness at $y_{v}$ must be overcome by a further increase in source strength - by an amount $V$ equal to the Vema sink.

The unrealistic choice $h_{N}=0$ forces separation to occur at or south of $y_{v}$ (Fig. 4) since there is no longer any bottom water north of the sink. In general, the range over which $y_{s}=y_{v}$ widens as $h_{N}$ is decreased, becoming infinite when $h_{N}=0$. If the separation occurs south of $y_{v}$, the "zonal" jet supplying the flow through the fracture zone cannot reach all the way to the western boundary and it too separates from the boundary farther south, at $y_{s}$.

Although the leak through the Vema Fracture Zone does not cause the transposition of bottom water from west to east in this model, it does accentuate this effect in proportion to its strength. The strength of the flow through the fracture must depend on west-east density differences, and these, in turn, depend on flow and mixing in the passage and in the eastern trough. Extending the model to include the eastern trough may allow the transport through the passage to be calculated rather than arbitrarily specified.

\section{e. Two moving layers}

One would like to know that the bottom water structure described above remains relevant when another water mass, represented by another layer, is moving above it. The next water mass up the water column is North Atlantic Deep Water, with a northern source and, therefore, tracer characteristics very dif- 
ferent from those of bottom water. The top of this layer is roughly $1500 \mathrm{~m}$ deep.

According to Worthington (1976), the total North Atlantic Deep Water source is about $10 \times 10^{6} \mathrm{~m}^{3} \mathrm{~s}^{-1}$, with $8 \times 10^{6} \mathrm{~m}^{3} \mathrm{~s}^{-1}$ of this leaving across the equator. Wright (1970) estimated that $9 \times 10^{6} \mathrm{~m}^{3} \mathrm{~s}^{-1}$ flows southward at $16^{\circ} \mathrm{N}$, most of which presumably leaves as well. These estimates imply a net source of (1-2) $\times 10^{6} \mathrm{~m}^{3} \mathrm{~s}^{-1}$, which suggests that the deep water source is substantially less than the bottom water source. The implication for upwelling is ambiguous because the weak additional mass source tends to be canceled by the greater area of the middepth interface.

If the cancellation is exact, there is no stretching and therefore no flow over that part of the basin occupied by bottom water. There is still stretching and flow in the northwest sector of the basin since the bottom layer is absent there and no compensating upwelling from below exists (Fig. 8).

The situation in which the two upwellings differed so that the second layer is stretched or compressed seems likely to produce very different circulation patterns in the two layers. To examine this question, the flow in two moving layers with a third overlying resting layer was calculated using the characteristic method of Luyten and Stommel (1986). Using this method, the upwelling at both interfaces is specified, resulting in either vortex stretching or compression in the deep layer. The results show that with uniform upwelling and grounding in the lower layer, the interior streamline pattern in either layer looks like the Stommel and
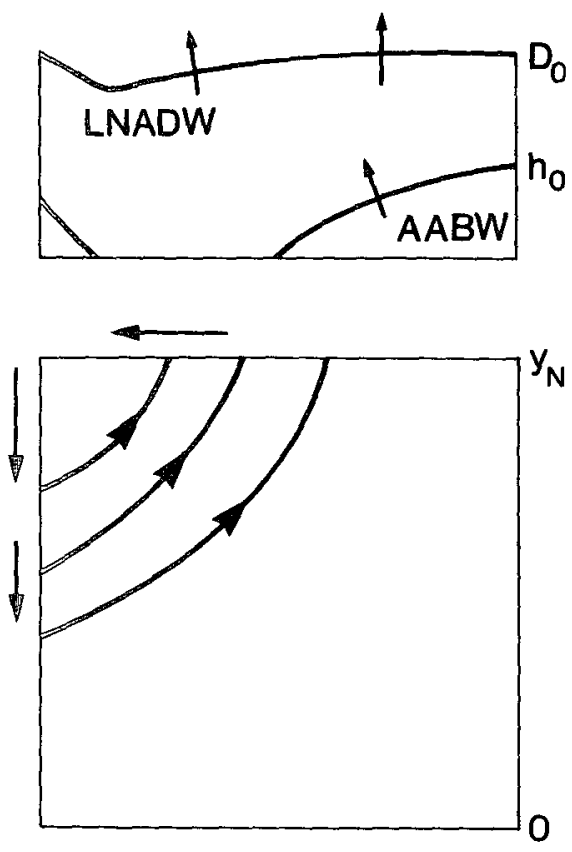

FiG. 8. Schematic of two-moving-layer system with equal upwelling. Cross section at a latitude north of $y_{s}$ (upper). Interface depth and flow direction in the second layer (lower).
Arons flow pattern (e.g., see Figs. 2 and 8 ). Of course, the direction of flow is reversed in the deep layer wherever vortex compression occurs. Integrating vertically through the two layers recovers the standard Stommel and Arons flow, as the depth variations of the upper interface are negligible.

Most of the water supplied by the northern source continues along the boundary and exits across the equator. As a result, the addition of the deep water layer is conceptually important to the flow field mainly at the western boundary, where the flow is not weak in this layer compared to the bottom layer (unlike the greater part of the interior).

These remarks are meant only to add some confidence to the application of the model to the bottom layer, in a basin where waters of diverse origin move relative to one another. Including more layers and necessarily covering the eastern basin as well would not appear, at this point, to change much the basic results already described for bottom water. Such extensions will be required, though, to understand how water at middepth moves around.

\section{Discussion}

In a deep basin fed by a source of dense water, a steady-state distribution of density requires vertical mixing and upwelling somewhere within it. Usually, mixing is expected when a local Richardson number made up of the vertical density gradient and the vertical shear of horizontal velocity at a given point falls below a certain critical value. However, such a local mixing process is difficult to incorporate into an analytical model. Assuming, instead, uniform mixing on the bottom layer interface results in simple analytic expressions for the structure of the layer in terms of a single parameter $\lambda$. For values of $\lambda$ less than a critical value, the interface grounds-confining the bottom layer to the eastern part of the basin. Water reaching the northern boundary returns south as an isolated boundary current and supplies a band of recirculating interior flow. Three major features of bottom water flow are united in this simple model: eastern intensification, isolated currents, and a recirculation.

To apply the results of this model to the flow in other basins, the distribution of sources and sinks must first be considered. For instance, both the eastern trough of the North Atlantic and the Angola Basin of the South Atlantic are similar to the western trough, since they have low-latitude sources of bottom water (Warren 1981). Their sources are weaker than that of the western trough, but the stratification is weaker too, and some of the isopycnals in these basins may behave similarly. Neither the Argentine Basin nor the Brazil Basin of the South Atlantic is analogous because they both have a source at one end (southern) and a sink at the other (Warren 1981). The boundary current connecting them carries the densest water along the 
entire length of the western boundary, making a true eastern intensification impossible. The same remarks apply to the South Pacific as a whole, since bottom water enters at the southwestern corner and exits at the northwestern corner, where it is the source for the North Pacific (Mantyla and Reid 1983). In general, the basic elements of the model presented here may be relevant when the bottom water source is on the equatorward side of the basin.

Acknowledgments. KGS thanks E. Tziperman and G. Johnson for helpful comment. The physical interpretation of $\lambda$ given here was adapted from that offered generously by a reviewer. Support for KGS came from a grant from the Ministère des Affaires Etrangèrs during a stay at IFREMER, Brest, France, and more recently from the Bundesministerium für Forschung und Technologie. MSM supported by NSF Grant OCE 8614486.

\section{REFERENCES}

Fuglister, F. C., 1960: Atlantic Ocean Atlas of Temperature and Salinity Profiles and Data from the International Geophysical Year of 1957-1958, Vol. 1, Woods Hole Oceanographic Institution Atlas Series, $209 \mathrm{pp}$.

Huang, R. X., 1984: The thermocline and current structure in subtropical/subpolar basins. Ph.D. dissertation, Massachusetts Institute of Technology and Woods Hole Oceanographic Institution Joint Program, 178 pp. [Available from MIT Document Library, Cambridge, MA.]

Kawase, M., 1987: Establishment of deep ocean circulation driven by deep-water production. J. Phys. Oceanogr., 17, 2294-2317.

Luyten, J. R., and H. Stommel, 1986: A beta-control of buoyancydriven geostrophic flows. Tellus, 38A, 88-91.
- J. Pedlosky, and H. Stommel, 1983: The ventilated thermocline. J. Phys. Oceanogr., 13, 292-309.

Mantyla, A. W., and J. L. Reid, 1983: Abyssal characteristics of the World Ocean waters. Deep-Sea Res., 30, 805-833.

McCartney, M. S., S. L. Bennett, and M. E. Woodgate-Jones, 1991: Eastward flow through the Mid-Atlantic Ridge at $11^{\circ} \mathrm{N}$ and its influence on the abyss of the eastern basin. J. Phys. Oceanogr., 21, 1089-1121.

Parsons, A. T., 1969: A two-layer model of Gulf Stream separation. J. Fluid Mechn., 39, 511-528.

Rhines, P. B., and P. M. McCready, 1989: Boundary control over the large-scale circulation. Parameterization of Small-Scale Processes, P. Mueller, Ed., Hawaii Institute of Geophysics special publication, University of Hawaii, Honolulu, 75-99.

Saunders, P. M., 1987: Flow through Discovery Gap. J. Phys. Oceanogr., 17, 631-643.

Speer, K. G., and E. Tziperman, 1990: Convection from a source in an ocean basin. Deep-Sea Res., 37, 431-446.

Stommel; H., and A. B. Arons, 1960: On the abyssal circulation of the World Ocean, Part I. Stationary planetary flow patterns on a sphere. Deep-Sea Res., 6, 140-154.

Warren, B., 1981: Deep circulation of the world ocean. Evolution of Physical Oceanography, Scientific Surveys in Honor of Henry Stommel, B. A. Warren and C. Wunsch, Eds., The MIT Press, 6-41.

Weatherly, G. L., and E. A. Kelley, 1985: Two views of the cold filament. J. Phys. Oceanogr., 15, 68-87.

Whitehead, J. A., 1989: Surges of Antarctic Bottom Water into the North Atlantic. J. Phys. Oceanogr., 19, 853-861.

Antarctic Bottom Water within the North Atlantic. J. Geophys. Res., 87, 7903-7924.

Worthington, L. V., 1976: On the North Atlantic Circulation. The Johns Hopkins Oceanographic Studies, No. 6, Johns Hopkins University Press, Baltimore, $110 \mathrm{pp}$.

_- and W. R. Wright, 1970: North Atlantic Ocean Atlas of Potential Temperature and Salinity in the Deep Water Including Temperature, Salinity and Oxygen Profiles from the Erika Dan Cruise of 1962, Woods Hole Oceanographic Institution Atlas Series, Vol. 2, 24 pp. and 58 plates.

Wright, W. R., 1970: Northward transport of Antarctic Bottom Water in the Western Atlantic Ocean. Deep-Sea Res., 17, 367-371. 